\title{
Aeromagnetic survey of the Somma-Vesuvius volcanic area
}

\author{
Valeria Paoletti $\left({ }^{1}\right)$, Robert Supper $\left({ }^{2}\right)$, Massimo Chiappini $\left({ }^{3}\right)$, Maurizio Fedi $\left({ }^{1}\right)$, \\ Giovanni Florio $\left(^{1}\right)$ and Antonio Rapolla $\left({ }^{1}\right)$ \\ (') Dipartimento di Scienze della Terra, Università degli Studi di Napoli «Federico II», Napoli, Italy \\ $\left(^{2}\right)$ Department of Geophysics, Geological Survey of Austria, Vienna, Austria \\ $\left.{ }^{3}\right)$ Istituto Nazionale di Geofisica e Vulcanologia, Roma, Italy
}

\begin{abstract}
In this paper we present and discuss the results of a geophysical airborne survey carried out in the Somma-Vesuvius volcanic area, Southern Italy, in 1999. The helicopter-borne survey was aimed at giving new detailed insights into the distribution of the magnetization of the area and, therefore, into the volcanological characteristics of the region, enhancing the knowledge given by a previous low resolution survey carried out at a regional scale by Agip. The new survey was carried out by flying on a surface parallel to the topography of the area, along flight lines spaced $600 \mathrm{~m}$ apart. The obtained total field map is dominated by a large anomaly related to the Mt. Somma-Vesuvius complex itself and characterized by a roughly elliptical shape. High-frequency anomalies occur in the edifice and in the area east of it, partly produced by cultural noise due to the densely inhabited area. The compilation of the maps of the analytic signal and of the horizontal derivative of the field allowed the location of the lateral boundaries of the magnetic sources of the area and represents a first step toward the interpretation of the maps in terms of geological structures.
\end{abstract}

Key words Somma-Vesuvius - aeromagnetic survey

\section{Introduction}

As is well known, the Vesuvius volcanic area is one of the most dangerous in the world because of the type of eruptions, mainly explosive, which characterize this volcano and of its location in a very densely populated area; for these reasons the study of its structural and volcanological features by geophysical methods has gained an increasing importance in the last few years. In this frame, the analysis of the aeromagnetic field can provide useful information on

Mailing address: Dr. Valeria Paoletti, Dipartimento di Scienze della Terra, Università degli Studi di Napoli «Federico II», Largo S. Marcellino, I-80138 Napoli, Italy; email:paoletti@unina.it subsurface magnetization distribution and can allow significant insights into the geological and volcanological characteristics of the area. The advantages of aeromagnetic with respect to ground magnetic surveying are: i) higher speed in collecting data, which implies lower costs and reduced effects on data of the magnetic field time variations; ii) better spatial coverage with respect to ground-based magnetic surveys, allowing surveying of areas inaccessible to ground work; iii) variable spatial resolution of the data, as the flight altitude can be tuned to favor imaging of magnetic effects from structures of different size and depth. For these reasons, in recent years the use of aeromagnetic surveys in volcanic areas has grown remarkably, also thanks to the differential Global Positioning System (DGPS) and to the developments that the interpretation methods underwent in the last decade, aiming at reducing ambiguity on the determination of the source characteristics (e.g., Fedi and Rapolla, 1999). 
Somma-Vesuvius is a strato-volcano characterized by products of both explosive and effusive eruptions. The complex, formed by an older volcanic center (Mt. Somma) and a more recent one (Mt. Vesuvius), is located in an area where a sedimentary, limestone basement sinks to depths of a few thousand meters b.s.l., as showed by gravity methods (Carrara et al., 1974) and seismic reflection data (Bruno et al., 1998). The Trecase 1 well, drilled inside the Vesuvius volcanic area, detected the sedimentary basement at about $1700 \mathrm{~m}$ b.s.l. (Bernasconi et al., 1981). The last eruption was in 1944 and closed a period of considerable activity which began with the violent 1631 eruption. After the 1944 eruption, which caused the conduit to remain closed, a quiescent period started. The presence of ejecta consisting of metamorphosed carbonate rocks (Barberi and Leoni, 1980) and the study of fluid inclusions of ejected nodules (Belkin and De Vivo, 1993) are the petrological indications of the possible presence of a shallow minor magma chamber. Rock magnetism measurements from Mt. Somma, Vesuvius and Trecase1 well (Cassano and La Torre, 1987) showed intense magnetization ranging from $6.8 \mathrm{~A} / \mathrm{m}$ (lavas from Vesuvius) to $0.5 \mathrm{~A} / \mathrm{m}$ (tuffs), with an average Koenigsberger ratio of about 8.6 and a total magnetization vector aligned in the direction of the present field.

Interpretation with 2.5D and 3D models (Fedi et al., 1998; Fedi and Rapolla, 1999) of a previous low resolution survey (Agip, 1981) showed high magnetizations inside the emergent part of the volcano and showed the presence of magnetized rocks down to a depth of about $2 \mathrm{~km}$ b.s.l. Recently, gravity studies (Cella et al., 2003) detected a deeper, intra-crustal low density source with an average density contrast compatible with a trachybasaltic body partially molten, which was interpreted as the main magmatic reservoir of the volcanic activity of the whole region. Rolandi et al. (2003), on the basis of a geo-volcanological study, subsequently also proposed the existence of a deep magmatic source, so confirming the above geophysical interpretation.

In order to obtain new more detailed information on the magnetization characteristics of the area, a detailed draped helicopter-borne survey was then carried out in October 1999. In the following we present the results of this aeromagnetic survey and the first analysis of the new data set of the Vesuvian volcanic area.

\section{The new aeromagnetic survey in the Vesuvian area}

\subsection{Technical and logistical characteristics of the survey}

The helicopter-borne survey covered an area of about 15 by $21 \mathrm{~km}$ (fig. 1). The flight lines, with a N-S azimuth, were spaced about $600 \mathrm{~m}$ apart, while the cross-track tie lines were spaced about $2 \mathrm{~km}$ apart. The sample spacing along each flight line was about $4 \mathrm{~m}$. An important feature of the survey was the variable flight elevation: unlike the Agip survey of 1981, performed at a constant altitude of $1460 \mathrm{~m}$ a.s.l. with survey lines $2 \mathrm{~km}$ apart, the new survey was characterized by a data acquisition along a surface roughly parallel to the topography of the area (draped acquisition), with a clearance of about $200 \mathrm{~m}$. This kind of acquisition, usually adopted in high resolution surveys, should allow the contribution to the magnetic field coming from an irregular terrain to be measured with the same detail, minimizing the effect of a magnetized terrain on the data (Bhattacharrya and Chan, 1977). The survey was affected by a few problems in the horizontal positioning very likely due to the cultural noise of the area. More specifically, no GPS signal was detectable in the area placed west of about $14^{\circ}, 43$ of east longitude. So the data along the lines flown west of this area were positioned comparing the images taken during the magnetic survey by an infrared video-camera mounted on the helicopter with detailed maps and aero-photographs of the area.

The instrumentation used for the survey was supplied by the Geological Survey of Austria and consisted of a ground and a flight section. The ground section contained two magnetometers used to monitor the external field activity during the flights and a GPS reference station used for the differential correction of satellite data. The flight section consisted of: i) a cesium magnetometer having a precision of $0.01 \mathrm{nT}$, which was contained in a «bird» flown $30 \mathrm{~m}$ be- 

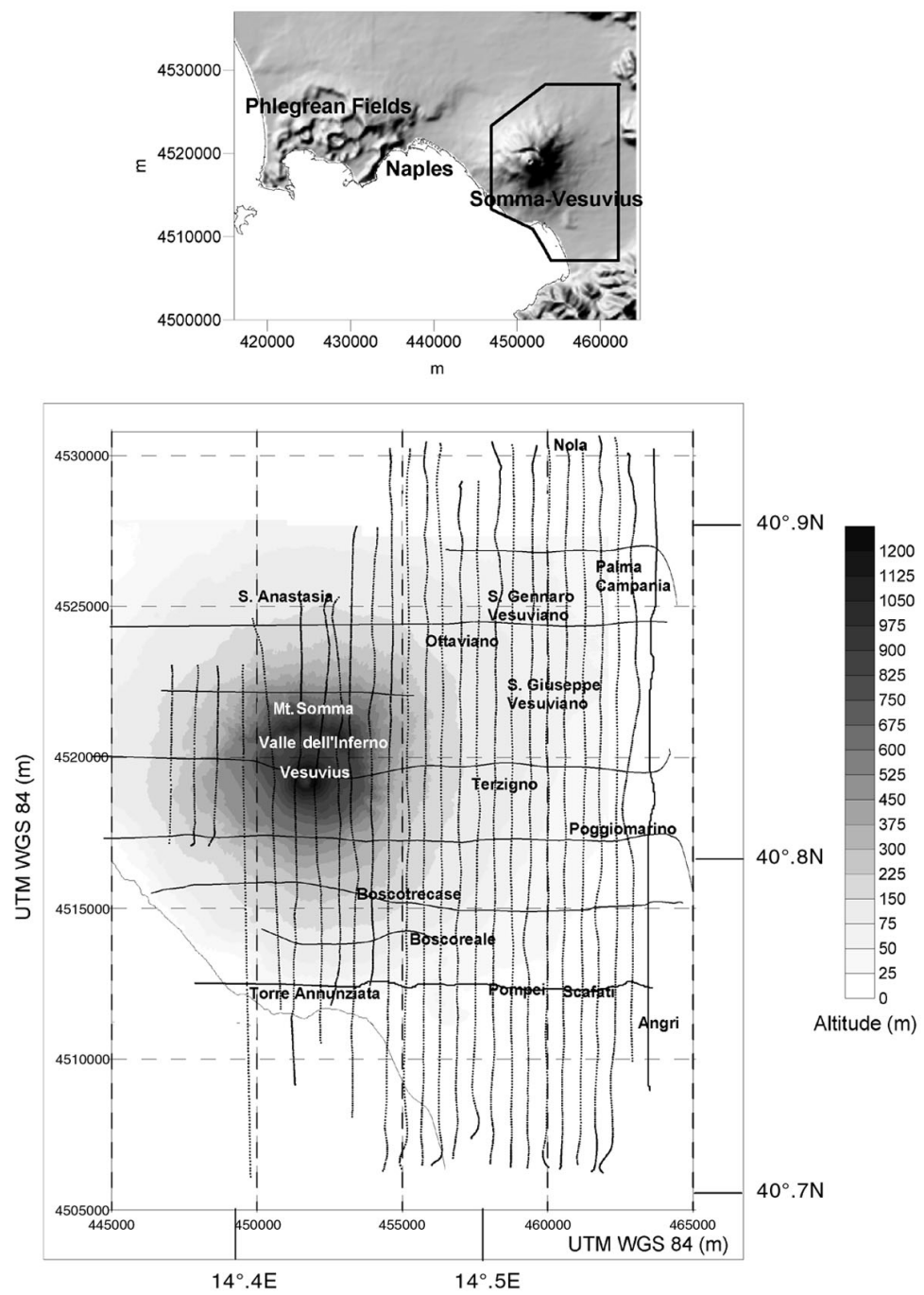

Fig. 1. Flight lines of the draped helicopter-borne survey performed in October 1999 in the Vesuvian area. The flight lines are $600 \mathrm{~m}$ apart, the tie lines are about $2 \mathrm{~km}$ apart and the sample spacing along the flight lines is 4 $\mathrm{m}$. Due to the cultural noise of the area, the satellite signal used by the Global Positioning System (GPS) was not detectable in the area placed west of $14^{\circ}, 43$ of east longitude.

low the helicopter; ii) a GPS sensor for the horizontal positioning of the helicopter, having a precision of $\pm 1 \mathrm{~m}$ after the differential correction; iii) a laser-altimeter for the vertical positioning of the helicopter; and iv) a computer for data acquisition.

\subsection{Data pre-processing}

The pre-processing of magnetic data accomplished by Supper and Paoletti allowed several data corrections and included the following steps: i) removal of spikes and gaps in the data; 
ii) flight path check and re-positioning, which consisted in removal of wrong coordinates and double records, differential correction of the GPS data and check of the flight altitude; iii) Earth's magnetic field diurnal variation corrections, which were also performed using the magnetic data of the Observatory of L'Aquila, Italy, as the magnetic data relative to the local base stations were often disturbed by the cultural noise of the area; iv) removal of the IGRF (International Geomagnetic Reference Field); v) statistical leveling, consisting in a minimization of the magnetic field time varying effects based on the differences between the field values measured at the crossing points between flight lines and tie lines; vi) decorrugation, a directional filtering to allow the removal of the directional anomalies still present along the flight lines after the leveling.

\section{The new aeromagnetic map of the Vesuvian volcanic area}

The magnetic data obtained after the pre-processing phase were then gridded to an interval of $150 \mathrm{~m}$ using a 3D interpolation that takes into account the variations of the field along the vertical direction too. The draped acquisition made a $3 \mathrm{D}$ data interpolation certainly more significant with respect to the commonly used 2D interpolation, which, in the case of high topographic gradients, would have led to some inaccuracy in the data gridding. The map obtained (fig. 2) is dom-

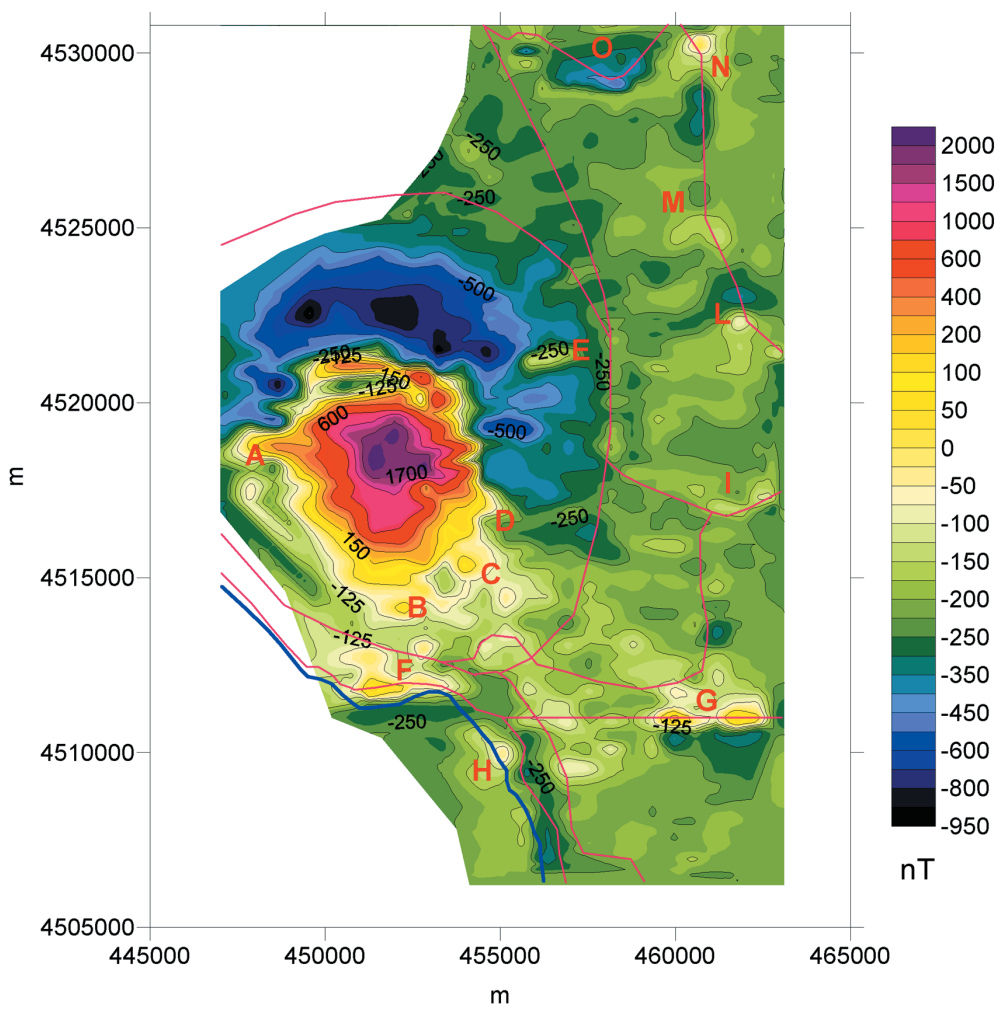

Fig. 2. The new magnetic map of the Vesuvian area obtained from the aeromagnetic survey performed in October 1999. The red lines show the railway lines, the blue line shows the coastline. For location of the anomalies see fig. 1. 

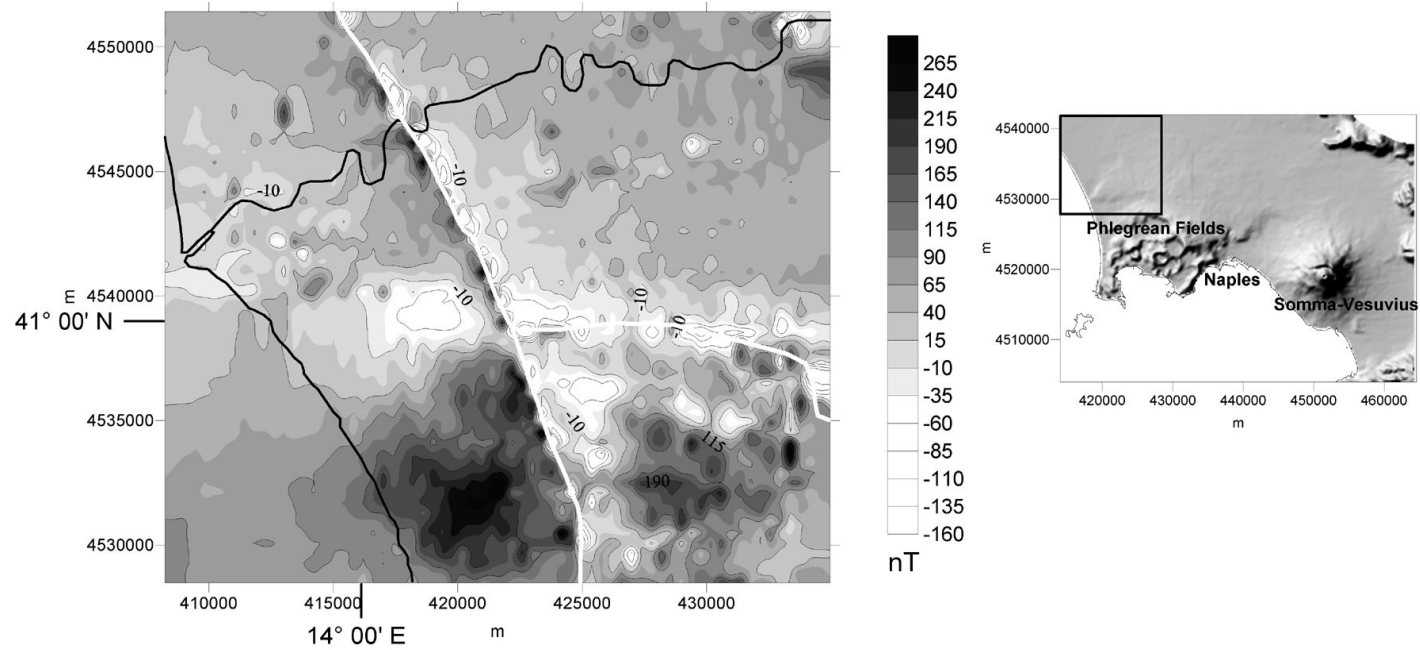

Fig. 3. Aeromagnetic field measured at $100 \mathrm{~m}$ above the surface relative to a survey carried out in Northern Phlegrean Fields in 1999-2000. The white lines show the railway line, the black line shows the coastline (from Paoletti et al., 2004).

inated by a large dipolar anomaly (amplitude of about $2500 \mathrm{nT}$ ) clearly related to the SommaVesuvius complex and characterized by a roughly elliptical shape elongated towards south. Remarkable features of the area at the base of the edifice are a narrow anomaly on the western slope of the edifice (A in fig. 2) and an irregular shape of the anomaly on the south-eastern slope of the volcano, where we observe some small anomalies (B, C and D). Finally, in the area north-east of the edifice, we notice an elliptical anomaly (E) and a general radial trend of the field. The presence of a double minimum in the summit area of the volcano, a bigger one placed north of Mt. Somma and a larger one placed above Valle dell'Inferno, seems instead due to altitude variations of the helicopter, as observed in a synthetic model reproducing the geometry of the data acquisition and the topography of the volcano. In fact, the survey was not perfectly draped in correspondence with the valley between Mt. Somma and Vesuvius (Valle dell'Inferno), where, due to the rough topography of the area, the clearance was bigger than the average clearance of the survey $(200 \mathrm{~m})$.
The areas surrounding the edifice are characterized by many high-frequency anomalies, which may be partly connected to the high cultural noise in the densely inhabited Vesuvian area. This area is in fact characterized by the presence of towns and buildings and an extensive network of railway lines which affect the magnetic field and are responsible, at least in part, for some of the measured anomalies. Previous studies (Linington, 1974) showed that the presence of electrified railway lines creates a magnetic dipole effect caused by currents flowing through the overhead voltage line and returning through the running rails. These train-induced signals, whose intensity and frequency varies with the position and number of the trains and the amount of current used by the trains (Larsen et al., 1996), may therefore cause intense dipolar magnetic anomalies aligned along the railway line. Figure 3 , relative to a survey performed in the nearby northern Phlegrean area (Paoletti et al., 2004), shows the linear effect due to the railway line between Rome and Naples. The data measured in the Vesuvian area do not show clear and intense linear effect and this makes it very difficult to 

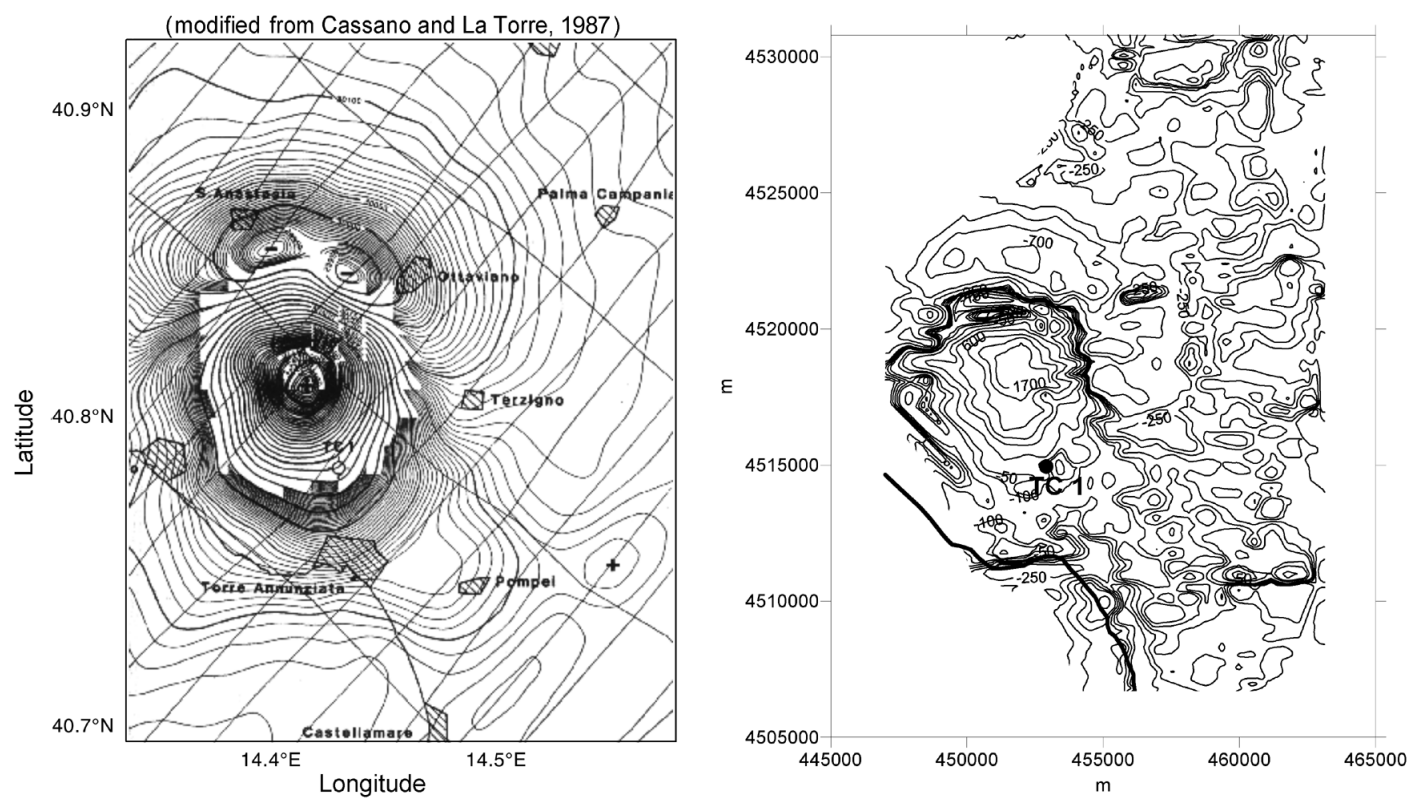

Fig. 4. Comparison between the aeromagnetic data set from 1999 (right) and the data acquired by Agip in 1981. The black dot in the right plot locates the Trecase1 well (TC 1).

distinguish between anomalies certainly due to noise and anomalies related to geology. Furthermore, while in some cases we cannot see any direct correlation between the anomalies and the presence of railway lines, some interesting anomalies are located in correspondence with a railway line. Among them, we notice two reversed anomalies of amplitude of about $250 \mathrm{nT}$ in the Torre Annunziata and Pompei-Scafati regions ( $F$ and $G$ in fig. 2), which seem to be aligned along a W-E trend. The presence of these reversed anomalies could be due to the effect of the cultural noise and/or to the presence of rocks originated during a period of inversion in the polarity of the magnetic field; a discussion about these reversed anomalies is presented in Section 5. As regards the anomaly measured in the area south of Nola ( $\mathrm{N}$ in fig. 2), it is not clear from this map if the anomaly has a normal polarity or is a reversed one. A clearer understanding of this aspect will come from the analysis of maps of the Analytic Signal (AS) and of the Horizontal Derivative (HD) of the field (see next section).
Other anomalies in correspondence to railway lines and characterized by an amplitude of about $100 \mathrm{nT}$ (see fig. 2) are placed along the coastline $(\mathrm{H})$, in the area of Poggiomarino (I), in the areas between S. Giuseppe Vesuviano and Palma Campania (L and M), and west of Nola (O). Finally, a group of anomalies trending NWSE from the Vesuvius edifice to the PompeiScafati area, through Boscotrecase and Boscoreale seems instead not correlated with any railway line.

A comparison between the new aeromagnetic data and the data acquired by Agip in 1981 at the constant altitude of $1460 \mathrm{~m}$ a.s.l. (fig. 4), in the frame of a regional survey (Cassano and La Torre, 1987) shows that thanks to the more detailed and draped acquisition in the new map the dipolar anomaly related to Somma-Vesuvius is remarkably more complex. In particular, we see that the old map does not show the anomalies along the slopes of the volcano (A, B, C, D and E in fig. 2). We notice instead that the elongation of the Somma-Vesu- 
vius anomaly to the south was already visible in the old map. As regards the areas surrounding the edifice, the comparison shows that the NW$\mathrm{SE}$ trend from the Vesuvius edifice through Boscotrecase and Boscoreale and the W-E trend through the towns of Torre Annunziata and Pompei were already highlighted in the old map, even if with much less detail. Finally, the new map is rich in high frequency anomalies not shown in the previous regional survey, except in the area of Pompei-Scafati, where a roughly defined anomaly was already detected.

\section{Analysis of the aeromagnetic data}

In order to better show the main anomalies and trends of the area and perform a reliable analysis of the magnetic data by the use of tech- niques of boundary analysis we carried out a high frequency filtering of the original data in fig. 2 by a method based on discrete wavelet transform (Fedi and Quarta, 1998), considering only the smallest scale. The magnetic map obtained after this low-pass filtering is shown in fig. 5 .

To locate the position of the magnetic sources of the anomalies of the area we computed a pole reduced map on the filtered data (fig. 6), assuming for the total magnetization vector the direction of the present inducing field in the area (inclination $=56^{\circ}$; declination $=0^{\circ}$ ). The reduction to the pole is a well-known linear transformation of the original field performed in the frequency domain which simplifies the shape of magnetic anomalies measured at intermediate latitudes, making them similar to the anomalies that would be measured above the

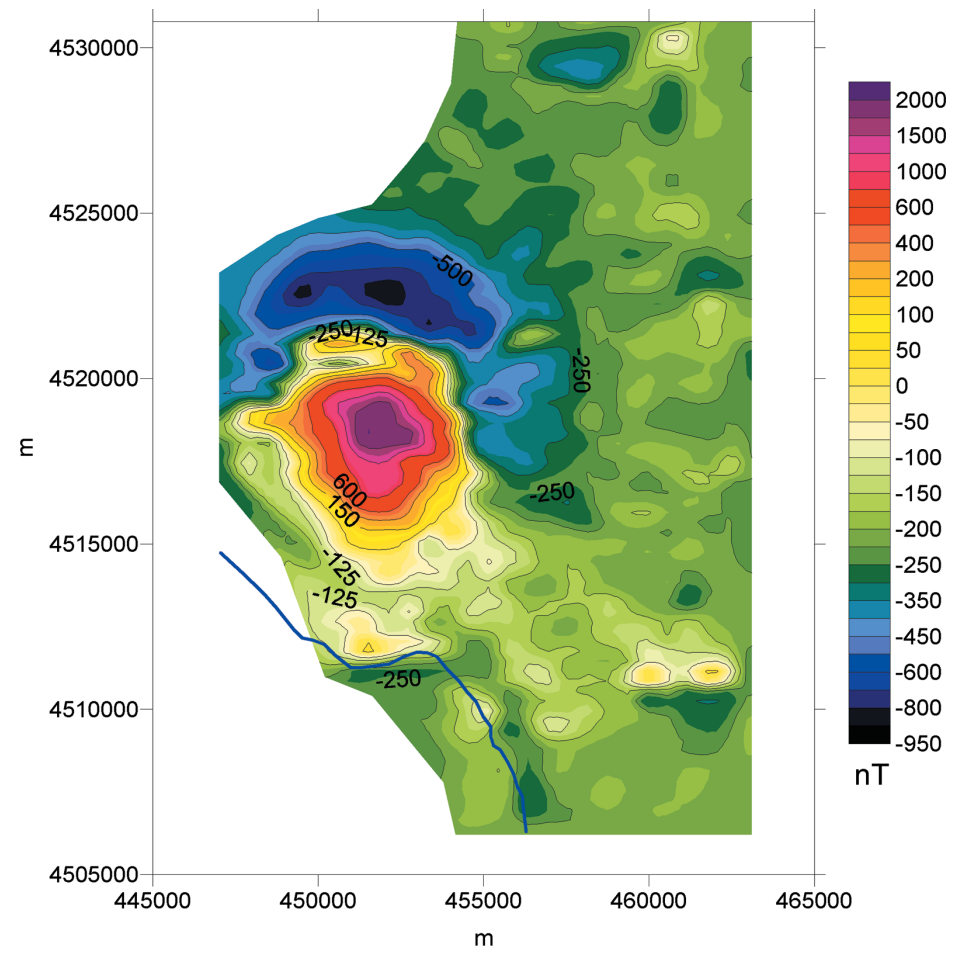

Fig. 5. High frequency filtered map of the new magnetic data set of the Vesuvian area. Coastline in blue. 


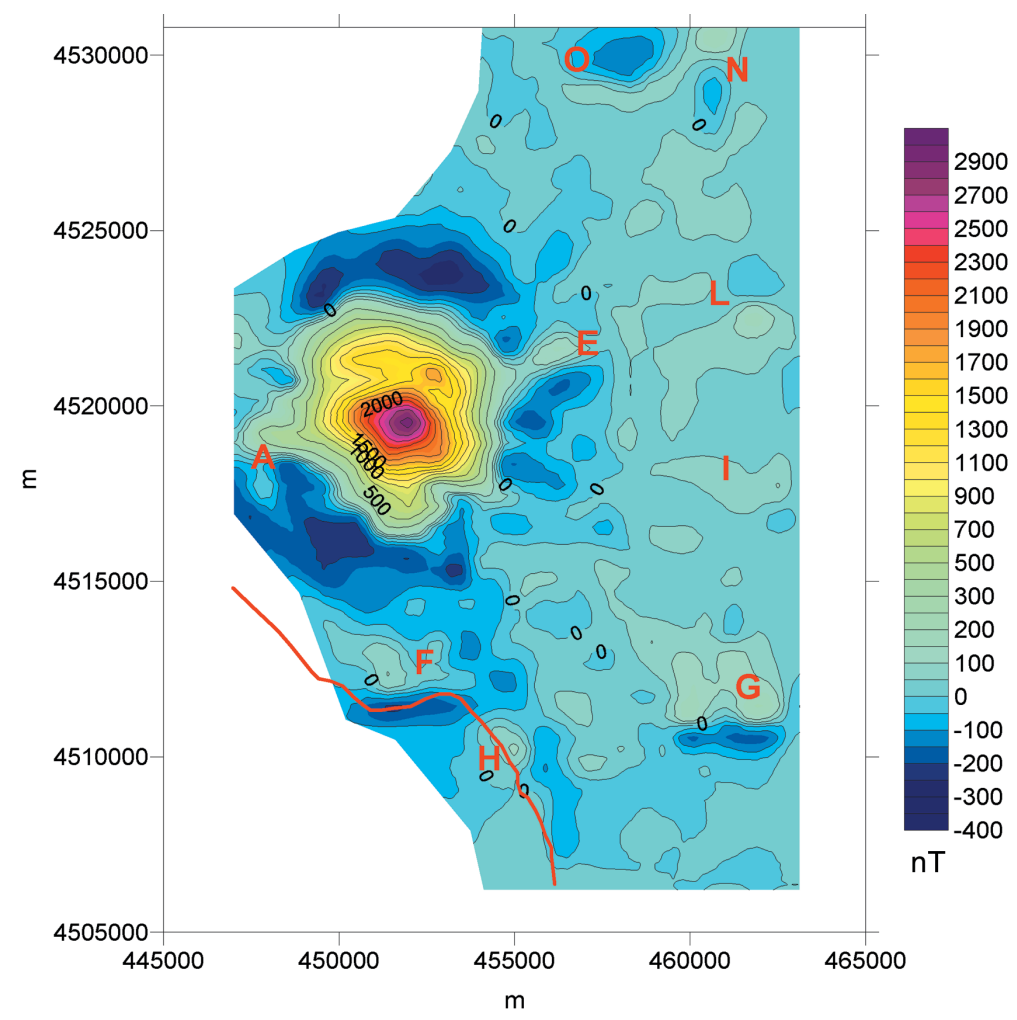

Fig. 6. Pole reduced map of the new magnetic data set of the Vesuvian area. Coastline in red.

same sources having vertical magnetization at the magnetic pole. If the direction of total magnetization vector is coincident with those of the present inducing field, a pole reduced anomaly is characterized by a shift of the anomaly just above its source. In fig. 6 we can indeed notice a shift northward, with respect to the field in figs. 2-5, of the anomalies relative to the Somma-Vesuvius and, in the surroundings, of the anomalies marked with $\mathrm{I}, \mathrm{L}, \mathrm{N}$ and $\mathrm{O}$. The anomaly related to the Somma-Vesuvius complex is characterized by two highs on the western and north-eastern slopes (A and E respectively in fig. 6) and has an irregular shape on the south-eastern slope. However, the direction of total magnetization vector in the whole surveyed area may be not constant and the map may therefore exhibits some badly distorted anomalies, as in the case of the reversed anomalies in the Torre Annunziata and PompeiScafati areas (F and $\mathrm{G}$ in fig. 6).

Some authors (Nabighian, 1984; Roest et al., 1992) showed the amplitude of analytic signal to have useful properties, being less sensitive to the direction of the magnetization vector and therefore helping to correlate the magnetic anomalies and their sources in a better way than the pole reduced map. In fact in cases of sufficiently high resolution and wide sources, the analytic signal presents its maxima directly over vertical and abrupt magnetization contrasts, otherwise it has a single bell shape over the source. However, it is well known (Agarwal and Shaw, 1996; Lin-ping et al., 1997; Linping and Zhi-ning, 1998) that the shape of the analytic signal is dependent on the direction of 
magnetization and, more specifically, on the value of the magnetic inclination; as a consequence, the maximum of this function is not always located directly over a dipolar source. These shifts are also a function of the source-toobservation distance (Salem et al., 2002). The map of the analytic signal of the Vesuvian area (fig. 7) presents the anomalies better centered over their sources, and shows a wide maximum area over the Vesuvius crater and some smaller maxima in the surroundings of the volcano. The maximum placed over the Somma-Vesuvius edifice is characterized by an irregular shape, which reveals a fairly complex pattern of the source distribution, while in the area around the edifice some interesting sources, which may be interpreted as small local vents, are clearly highlighted (F-G-H-I-L-O in fig. 7). The ana- lytic signal map also shows that the anomaly south of Nola, which in fig. 2 appeared as possibly reversed (and was marked with $\mathrm{N}$ ), seems instead to be caused by two separate sources with a normal polarity, marked in fig. 7 with $\mathrm{N}$ and $\mathrm{P}$.

To locate the lateral boundaries of the magnetic sources we plotted the maxima of the horizontal derivative of the pole reduced magnetic field. Cordell and Grauch (1985) showed in fact that the maxima of the horizontal derivative of pole reduced magnetic anomalies are located above changes in magnetization. However, according to Grauch and Cordell (1987) when the boundaries are not represented by a vertical contact or when several boundaries are close together the location of the gradient maximum can be offset from the boundary; the amount of

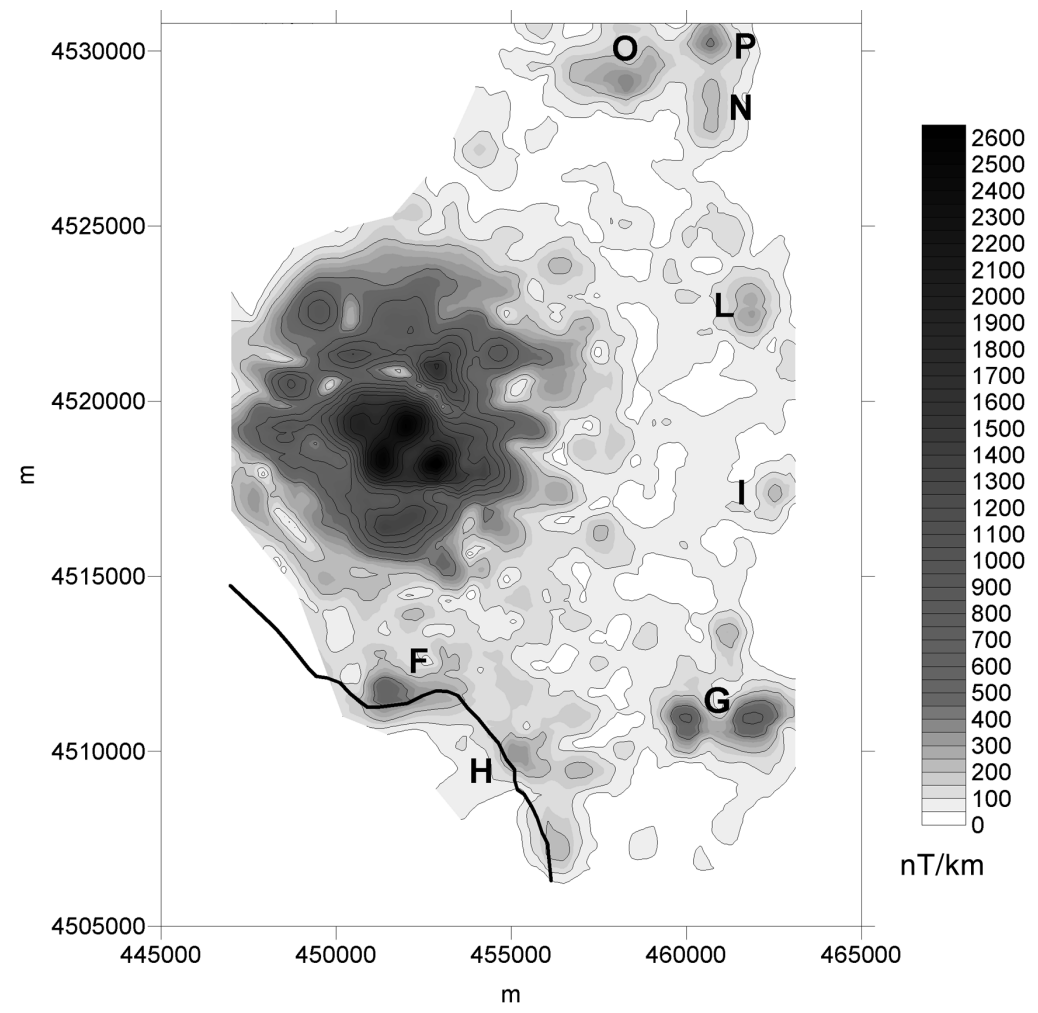

Fig. 7. Map of the analytic signal of the magnetic field of the Vesuvian area. 
this offset is determined by the depth of the top edge of the boundary below the observation and by the dip of the boundary. The analytic signal method is also affected by an offset in the presence of dipping contacts.

The map of the horizontal derivative of the pole reduced magnetic field (fig. 8) shows some maxima in the edifice area south of the crater at an altitude of about $750 \mathrm{~m}$ a.s.1. and corresponding fairly well to the southern caldera rim of Mt. Somma inferred by Rosi et al. (1987); this boundary is actually characterized by a slight shift northward with respect to the rim quoted in Rosi et al. (1987). The same map also highlights an isolated magnetic source south of this rim, at an altitude of about $500 \mathrm{~m}$ a.s.l. This source corresponds to the elongation to the south of the dipolar anomaly related to the edifice (see fig. 2) and to an high in the map of the analytic signal (see fig. 7), and it is not apparently related to any relevant outcrop in the map of Rosi et al. (1987). In the northern part of the edifice the horizontal derivative map appears influenced by the characteristics of the acquisition geometry (see Section 3) and therefore the shown rims cannot be fully trusted.

As regards the surrounding areas, the map shows the magnetic anomaly pattern of the lateral boundaries of some small local vents $(\mathrm{L}, \mathrm{N}$, $\mathrm{P}$ and $\mathrm{O}$ in fig. 8) and suggests the presence of some linear trends:

- A NE-SW linear trend, which seems to start from the north-eastern rim of Mt. Somma, possibly consistent with a trend detected by a boundary analysis performed on gravity data (Florio et al., 1999), by an analysis of the gravity gradient tensor (Fedi et al., 2004) and by reflection seismic studies (Bruno et al., 1998).

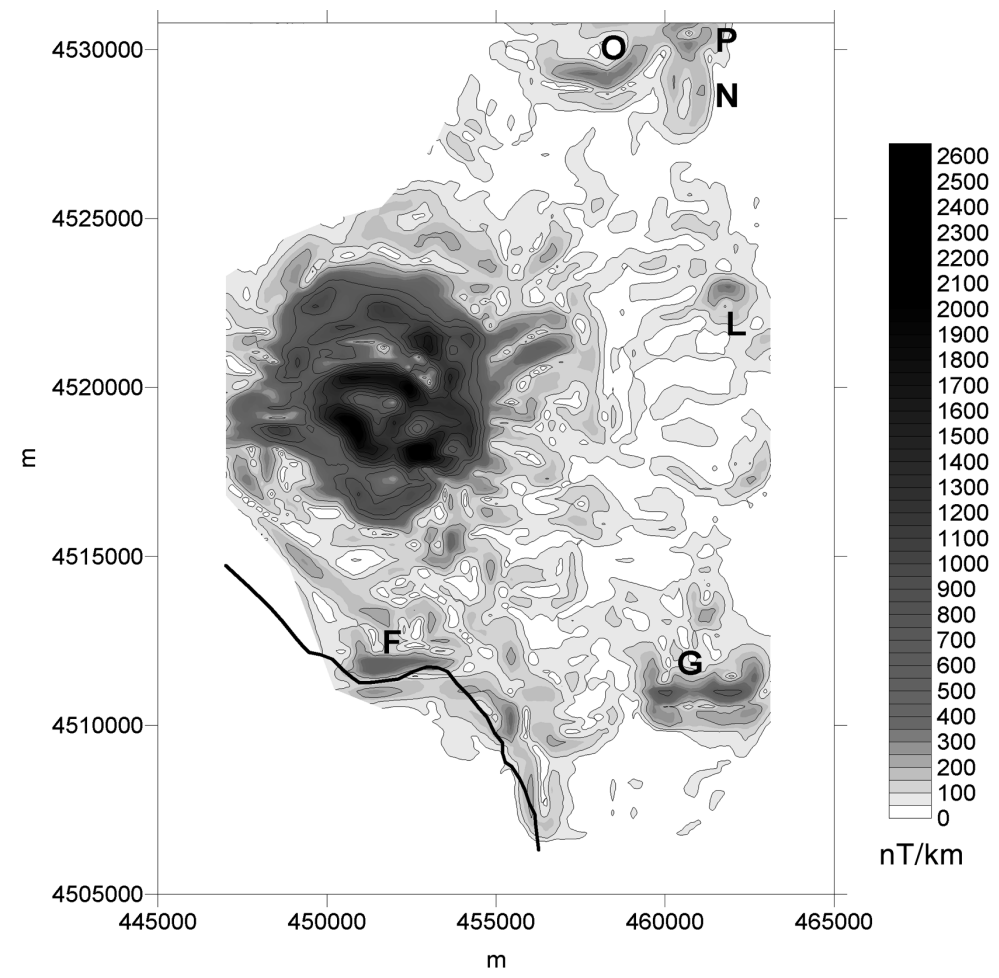

Fig. 8. Map of the Horizontal Derivative of the pole reduced magnetic field of the Vesuvian area. 
- A NW-SE trend from the south-eastern rim of the volcano, running parallel to the coastline, and already shown by gravity (Fedi et al., 2004) and seismic (Bruno et al., 1998) studies.

- A W-E trend, which appears to be cut by the NW-SE trend and is formed by the anomalies measured in the areas of Torre Annunziata and Pompei-Scafati (F and G in fig. 8); this magnetic trend is possibly consistent with a trend highlighted by gravity studies (Florio et al., 1999; Fedi et al., 2004) and with geochemical studies which measured a $\mathrm{CO}_{2}$ emission in the same areas (Caliro et al., 1998).

In conclusion, while the HD data allow the pattern of some linear trends in the areas surrounding the edifice to be detected, both the AS and the HD maps clearly locate the southern caldera rim of Mt. Somma and highlight the position of some local vents in the areas around the volcano.

\section{Correlation between magnetic anomalies and railway lines and study of the possible origin of the reversed anomalies of the Vesuvian area}

As mentioned, the data may somehow have been influenced by the cultural noise connected to the railway lines of the area and this makes it difficult to distinguish between anomalies due to noise and anomalies related to geology. Therefore we tried to perform a denoising in the signal aimed to reduce the influence of the railway lines by a method based on discrete wavelet transform (Fedi and Quarta, 1998). The filtering, performed using a triangular base wavelet, was carried out specifying a region straddling the railway lines about $4 \mathrm{~km}$ wide and considering the two smallest scales. More specifically, we removed the details contained in both the 6th and the 7 th scales, corresponding to a wavelength of the analysing wavelet of about 600 and $300 \mathrm{~m}$, respectively. The denoising process was carried out in the NS, EW and diagonal directions. The parameters used in the filtering were chosen on the basis of studies on the anomalies induced by the railway lines conducted by Senanayake (1990), Palangio et al. (1991), Santarato et al. (1994) and Iliceto and Santarato
(1999). According to these authors the train-induced magnetic field decreases as the square of the distance from the line and can be of 5-35 nT at a distance of 1-2 $\mathrm{km}$ from the line. We chose the width of the region straddling the railway line and the scales to be filtered also on the basis of a previous denoising successfully applied to the nearby northern Phlegrean area (see Fedi et al., 2003; Paoletti et al., 2004); this area is in fact characterized by anomalies that are clearly train-induced.

The excellent space-scale localization properties of this method allowed a very sharp and space-localized filtering along the railway lines in the Vesuvian area, leaving the field in adjacent areas unchanged (fig. 9). As we can notice, the application of this filtering procedure to our case did not remove, but only slightly modified, the anomalies in correspondence to the railway lines (see, e.g., $\mathrm{F}$ and $\mathrm{G}$ in fig. 9).

For a correct evaluation of these results one should take into account the variable characteristics of the railway effect, that may induce secondary magnetic fields of different extent depending on the local geology. Moreover, these magnetic fields are highly variable in time and space, depending on number and position of the trains running along the railway line-section (Larsen et al., 1996; Buccella and Feliziani, 2003) and this may explain why the data measured in the Vesuvian area do not show a clear and constant presence of dipolar magnetic anomalies aligned along the railway lines. However, the evidence of other related geophysical and geochemical anomalies in the same zone (see previous section) gives another indication on the presence of sources of geologic origin in the Pompei-Scafati area. In conclusion, all these elements seem to suggest a superimposition of geological and antropic effects, at least in some of the investigated areas.

The evidence we highlighted allowed us to entertain the possibility that the sources of some reversed anomalies south of the SommaVesuvius edifice ( $\mathrm{F}$ and $\mathrm{G}$ in fig. 2) are mainly connected to geology. Working in this hypothesis, we now try to make some hypotheses on their origin as possibly connected to a period of inversion in the polarity of the magnetic field. As is known, the last inversion in the polarity of 


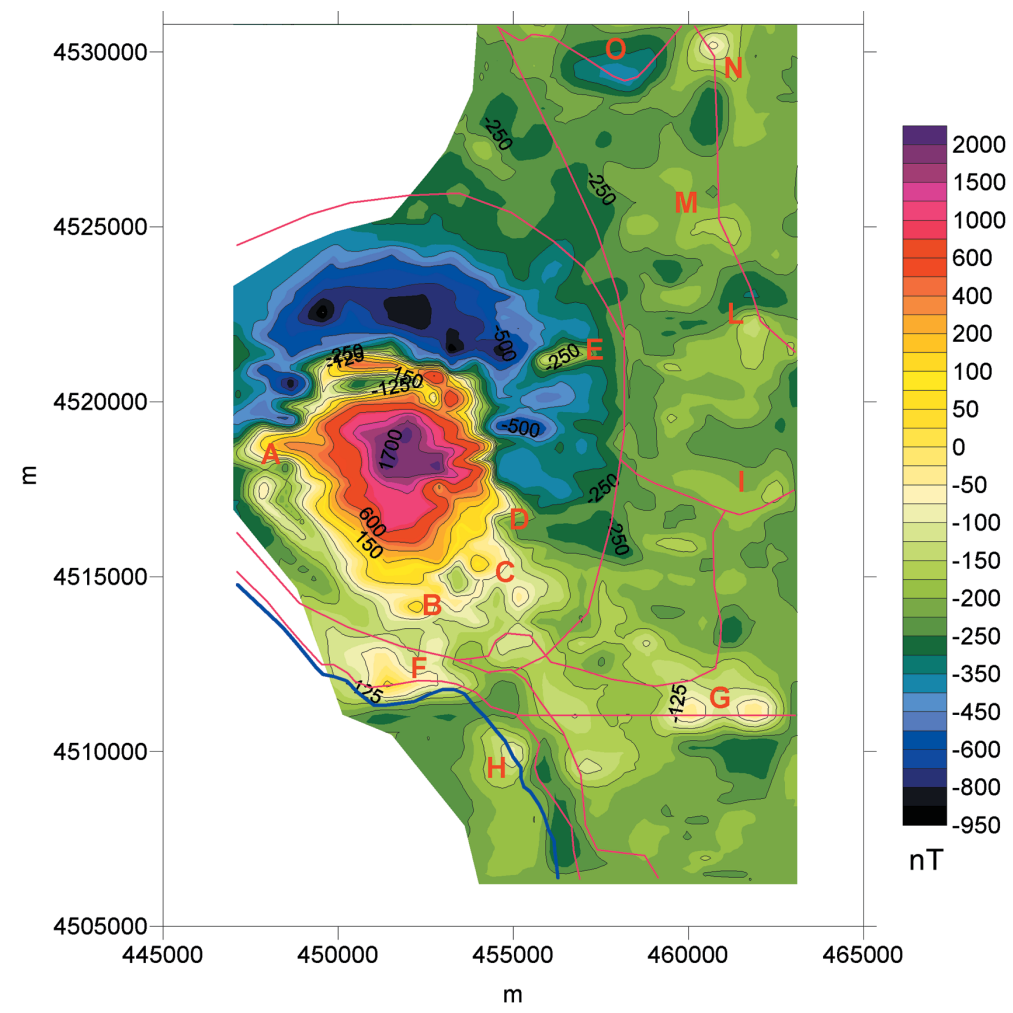

Fig. 9. Filtered map (localized filtering along the railway lines) of the new magnetic data set of the Vesuvian area. The red lines show the railway lines, the blue line shows the coastline.

the Earth magnetic field was recorded $778 \mathrm{kyr}$ ago (Cande and Kent, 1995), marking the limit between the Matuyama and the Brunhes epochs, while the three main excursions during the Bhrunes epoch recognized as truly global in extent are the Blake, Laschamp and Mono Lake events, dated $12 \pm 14 \mathrm{kyr}, 47-43 \mathrm{kyr}$ and $32-25$ kyr respectively (Singer et al., 2002). In order to understand whether the sources of these reversed anomalies belong to the Matuyama epoch or to one of the excursions recorded during the Bhrunes epoch, we considered the depth to the body sources and correlated this depth with the age of the rocks found at the same depth in a well drilled in the Vesuvian area.

The depths to the sources of the anomalies of Pompei-Scafati and Torre Annunziata areas were studied by the analysis of the power spec- tra along profiles (Fedi et al., 1997) using the method of maximum entropy (Burg, 1975). The analysis of the power spectra of the profiles measured in the two areas resulted in a depth of 210-230 m b.s.1. (Paoletti, 2002). This outcome excludes that these sources originated during the Matuyama epoch, whose products according to the Trecase 1 well (Principe et al., 1987) (see fig. 4) should be placed at greater depths, and suggests a more recent origin of these rocks connected to excursions recorded during the Brunhes epoch. To try to date these sources, we referred to the Campanian ignimbrite deposits (37-35 kyr) found in the Trecase1 well (Principe et al., 1987), whose depth ranges from $105 \mathrm{~m}$ (top) to $180 \mathrm{~m}$ (bottom) b.s.l. This result suggests a possible pre-ignimbritic origin of the body sources of the reversed anomalies, tenta- 
tively connected to the activity of small local vents occurred 47-43 kyr, during the Laschamp excursion (Singer et al., 2002).

Moreover, the absence of minerals of the ilmenite-hematite series in the Vesuvius lavas (Joron et al., 1987) seems to exclude an origin of these sources connected to auto-inversion phenomena, as these phenomena take can place only in deposits containing a volume percentage of minerals of the ilmenite-hematite series ranging between $0.4 \%$ and $0.6 \%$ (Tarling, 1983).

\section{Conclusions}

We presented the results of a recent aeromagnetic survey carried out in the SommaVesuvius volcanic area aimed at giving new detailed insights into the distribution of the magnetization of the subsurface. The map of the total magnetic field is dominated by a large anomaly related to the Somma-Vesuvius complex and characterized by a roughly elliptical shape, while the areas surrounding the edifice are characterized by many high-frequency anomalies, which may be partly connected to the high cultural noise in the Vesuvian densely inhabited area. Some anomalies seem in fact to be correlated to the presence of the railway lines of the area; they also exhibit, however, major superposition with geological features identified by other geophysical and geochemical methods. Assuming therefore that the reversed anomalies singled out in the areas of Pompei-Scafati and Torre Annunziata (marked with $F$ and $G$ in figs. 2, 6-9) are of geological origin, we were able to infer a possible pre-ignimbritic origin of their sources, very likely connected to the activity of small local vents during one of the polarity excursions recorded in the Brunhes epoch. A new high resolution survey in the above mentioned areas would allow us to verify the repeatability of the measurements and checking the nature, antropic or geologic, of the sources; the repeatability of the measures would in fact witness a stationary effect, quite different from the EM noise related to the presence of railway lines. Details on the EM noise produced by electrified railways lines on magnetotelluric and geomagnetic measurements can be found in Palangio et al. (1991) and Iliceto and Santarato (1999).

A first interpretation of the data set in terms of geological structures was given by the analysis of the analytic signal and of the horizontal derivative of the field, which allowed us to locate the lateral boundaries of the magnetic sources and disclose the pattern of the linear trends of the area. The map of the analytic signal revealed a fairly complex pattern of the source distribution in the edifice area, while in the area around the volcano some interesting sources, which may be interpreted as small local vents, were clearly shown (F-G-H-I-L-O-P in fig. 7).

The map of the horizontal derivative of the pole reduced magnetic field (fig. 8) showed some maxima in the edifice area south of the crater and corresponding fairly well with the southern caldera rim of the Mt. Somma inferred by Rosi et al. (1987). The same map also highlighted an isolated magnetic source south of this rim corresponding to the elongation to the south of the dipolar anomaly related to the edifice (see fig. 2) and to an high in the map of the analytic signal (see fig. 7) and not apparently related to any relevant outcrop in the map of Rosi et al. (1987). In the area surrounding the edifice the map detected the magnetic anomaly pattern of the lateral boundaries of some small sources (L, N, P and $\mathrm{O}$ in fig. 8) and showed three main linear magnetic trends: a NE-SW, a NW-SE and a W-E trend. These lineaments partially overlap with existing railway lines but they also correlate with geological features already inferred in previous gravity, seismic and geochemical studies.

In conclusion, the obtained results represent a first step for a complete interpretation of the data in terms of geo-volcanological structures; further details on the volcanological significance of several local magnetic sources in the Vesuvian area shall be discussed in a separate paper.

\section{Acknowledgements}

The work was partially financed thanks to an OV-GNV grant to one of us (A.R.). The authors thank the Geological Survey of Austria for the cooperation and are grateful to CIRAM, 
University of Naples, for providing the data about the location of the railway lines. The authors are also grateful to an anonymous reviewer for constructive comments on our paper.

\section{REFERENCES}

Agarwal, B.N.P. and R.K. SHaw (1996): Comment on 'An analytic signal approach to the interpretation of total field magnetic anomalies' by Shuang Qin, Geophys. Prospect., 44, 911-914.

AgIP (1981): Carta Aeromagnetica d'Italia (scala 1:500 000), Att. Min., Direz. Espl. Idrocarburi, S. Donato Milanese.

BARBERI, F. and L. LEONI (1980): Matamorphic carbonate ejecta from Vesuvius plinian eruptions: evidence of the occurrence of shallow magma chambers, Bull. Volcanol., XLIII (1), 107-120.

Belkin, H.E. and B.D. DE Vivo (1993): Fluids inclusions studies of ejected nodules from plinian eruptions of Mt. Somma-Vesuvius, J. Volcanol. Geotherm. Res., 58 (1/4), 89-100.

Bernasconi, A., P. Bruni, L. Gorla, C. Principe and A. SBRANA (1981): Risultati preliminari dell'esplorazione geotermica profonda nell'area vulcanica del SommaVesuvio, Rend. Soc. Geol. It., 4, 237-240.

BHATTACHARRYA, B.K. and K.C. CHAN (1977): Reduction of magnetic and gravity data on an arbitrary surface acquired in a region of high topographic relief, Geophysics, 42, 1411-1430.

Bruno, P.P.G., G. Cippitelli and A. Rapolla (1998): Seismic study of Mesozoic carbonate basement around Mt. Somma-Vesuvius, Italy, J. Volcanol. Geotherm. Res., 84, 311-322.

Buccella, C. and M. Feliziani (2003): Calcolo e misura del campo magnetico all'interno di un treno ad alta velocità con elettrificazione in corrente alternata, in Convegno Nazionale «Strumenti e tecniche di misura per la protezione dell'uomo e dell'ambiente dai campi elettromagnetici», Area di Ricerca CNR di Firenze, 28-29 Maggio, 2003, Sesto Fiorentino (FI).

BuRG, J.P. (1975): Maximum entropy spectral analysis, Ph.D. Thesis (Stanford University).

Caliro, S., C. Panichi and D. Stanzione (1998): Vaseline study of the isotopic and chemical composition of waters associated with the Somma-Vesuvio volcanic system, Acta Vulcanol., 10, 19-25.

CANDE, S.C. and D.V. KENT (1995): Revised calibration of the geomagnetic polarity timescale for the Late Cretaceous and Cenozoic, J. Geophys. Res., 100 (B4), 6093-6095

Carrara, E., F. Iacobucci, E. Pinna and A. Rapolla (1974): Interpretation of gravity and magnetic anomalies near Naples, Italy, using computer techniques, Bull. Volcanol., XXXVIII (2), 1-10.

Cassano, E. and P. LA Torre (1987): Geophysics, in Somma-Vesuvius, edited by R. SANTACroce, Quad. Ric. Sci., 114 (8), 175-183.

Cella, F., M. Fedi, G. Florio, M. Grimaldi, V. Paoletti and A. Rapolla (2003): Deep and shallow structure of Somma-Vesuvius volcano from potential field data interpre- tation, in Workshop «Vesuvius: Inside the Volcano», May 8-10, 2003, Ercolano (Italy), abstr. vol., p. 11.

Cordell, L. and V.J.S. Grauch (1985): Mapping basement magnetization zones from aeromagnetic data in the San Juan Basin, New Mexico, in The Utility of Regional Gravity and Magnetic Anomaly Maps, edited by W.J. HINZE (Society of Exploration Geophysics), 181197.

FEDI, M. and T. QUARTA (1998): Wavelet analysis for the regional-residual and local separation of potential field anomalies, Geophys. Prospect., 46, 507525.

FEDI, M. and A. RAPOLLA (1999): 3D inversion of gravity and magnetic data with depth resolution, Geophysics, 64, 452-460.

FEDI, M., T. QuARTA and A. DE SANTIS (1997): Inherent power law behavior of magnetic filed spectra from spector and grant ensemble, Geophysics, 62, 1143-1150.

FEDI, M., G. Florio and A. RAPOLla (1998): 2.5D modeling of Somma-Vesuvius structure by aeromagnetic data, J. Volcanol. Geotherm. Res., 82, 239-247.

Fedi, M., G. Florio, V. Paoletti, A. Rapolla and R. SupPER (2003): Analysis and interpretation of aeromagnetic data affected by intense cultural noise, in 65th EAGE Conference, Stavanger, Norway, abstr. E-33.

Fedi, M., G. Florio, F. Italiano and A. Milia (2004): Campanian Plain, Southern Italy: correlation between geological structures and Gravity Gradient Tensor (GGT) components, in SEG Special Volume about 'Gravity Gradient Tensor' (submitted).

Florio, G., M. Fedi, F. Cella and A. Rapolla (1999): The Campanian Plain and Phlegrean Fields: structural setting from potential field data, J. Volcanol. Geotherm. Res., 91, 361-379.

Grauch, V.J.S. and L. Cordell (1987): Limitations of determining density or magnetic boundaries from the horizontal gradient of gravity or pseudogravity data, Geophysics, 52, 118-121.

Iliceto, V. and G. SANTARAto (1999): On the interference of man-made EM fields in the magnetotelluric 'dead band', Geophys. Prospect., 47, 707-719.

Joron, J.L., N. Métrich, M. Rosi, R. SAntacroce and A. SBRANA (1987): Chemistry and petrography, in Somma-Vesuvius, edited by R. SANTACROCE, Quad. Ric. Sci., 114 (8), 105-174.

Larsen, J.C., R.L. Mackie, A. Manzella, A. Fiordelisi and S. RIEVEN (1996): Robust smooth magnetotelluric tranfer functions, Geophys. J. Int., 124, 801-819.

LININGTON, R.E. (1974): The magnetic disturbances caused by DC electric railways, Prospezioni Archeologiche, $\mathbf{9}$, 9-20.

LIN-PING, H. and G. ZHI-NING (1998): Discussion on 'Magnetic interpretation using the $3 \mathrm{D}$ analytic signal' by W.R. Roest, J. Verhoef and M. Pilkington, Geophysics, 63, 667-670.

LiN-PING, H., G. ZHI-NING and Y. CHANG-LI (1997): Comment on 'An analytic signal approach to the interpretation of total field magnetic anomalies' by Shuang Qin, Geophys. Prospect., 45, 879-881.

NABighian, M. (1984): Toward a three-dimensional automatic interpretation of potential field data via generalized Hilbert transforms: fundamental relations, Geophysics, 49, 780-786.

Palangio, P., M. Marchetti and L. Di Diego (1991): Ru- 
more elettromagnetico prodotto dalle ferrovie elettrificate, effetti sulle misure magnetotelluriche e geomagnetiche, in Atti del X Convegno Nazionale GNGTS, Roma, 745-760.

PAoletTI, V. (2002): Indagini aeromagnetiche nell'area vulcanica vesuviana, Ph.D. Thesis (Dipartimento di Geofisica e Vulcanologia, Università degli Studi di Napoli «Federico II»).

Paoletti, V., M. Fedi, G. Florio, R. Supper and A. RapolLA (2004): The new integrated aeromagnetic map of the Phlegrean Fields volcano and surrounding areas, Ann. Geophys., 47 (5), 1569-1580.

Principe, C., M. Rosi, R. Santacroce and A. Sbrana (1987): Explanatory notes to the geological map, in Somma-Vesuvius, edited by R. SANTACroce, Quad. Ric. Sci., 114 (8), 11-52.

Roest, W.R., J. Verhoef and M. Pilkington (1992): Magnetic interpretation using the 3D analytic signal, Geophysics, 57, 116-125.

Rolandi, G., F. Bellucci, M.T. Heizler, H.E. Belkin and B. DE VIVo (2003): Tectonic controls on the genesis of ignimbrites from Campanian Volcanic Zone, Southern Italy, Mineral. Petrol., 79 (1/2), 3-31.

Rosi, M., R. SAnTACroce and A. Sbrana (Editors) (1987): Geological map of Somma-Vesuvius volcanic com- plex, in Somma-Vesuvius, edited by R. SANTACroce, Quad. Ric. Sci., 114.

Salem, A., D. Ravat, T.J. GameY and K. UshiJima (2002): Analytic signal approach and its applicability in environmental investigations, J. Appl. Geophys., 49, 231-244.

Santarato, G., U. Spagnolini and V. Iliceto (1994): Caratterizzazione del rumore elettromagnetico prodotto dalle ferrovie elettrificate, in Atti del XIII Convegno Annuale del Gruppo Nazionale di Geofisica della Terra Solida, Roma, Italy, 635-638.

SENANAYAKE, W.E. (1990): An investigation of magnetic effects associated with DC electrified trains, Boll. Geofis. Teor. Appl., 32, 275-283.

Singer, B.S., M.K. Rell, K.A. Hoffman, A. Battle, C. LaJ, H. Guillou and J.C. Carracedo (2002): Ar/Ar ages from transitionally magnetized lavas on La Palma, Canary Islands, and the geomagnetic instability timescale, J. Geophys. Res., 107 (B11).

Tarling, D.H. (1983): Paleomagnetism. Principles and Applications in Geology, Geophysics and Archaeology (Chapman and Hall Ltd.), pp. 379.

(received July 29, 2003; accepted December 22, 2004) 